\title{
Characteristics of student engagement in high-school robotics courses
}

\author{
Igor M. Verner ${ }^{1}$ (D) $\cdot$ Huberth Perez ${ }^{1} \cdot$ Rea Lavi $^{2}$
}

Accepted: 17 June 2021 / Published online: 28 June 2021

(C) The Author(s), under exclusive licence to Springer Nature B.V. 2021

\begin{abstract}
Student engagement has been described as active involvement in a learning activity that significantly affects learning achievement. This study investigated student engagement in robotics education, considering it as an instant emotional reaction on interaction with the teacher, the peers, and the robotic environment. The objective was to characterize engagement in high school robotics courses through the lenses of preparation for academic and technical careers. Students who participated in this study $(\mathrm{N}=41)$, all of whom were in the eleventh grade, belonged to either School A $\left(n_{1}=20\right)$ or School B $\left(n_{2}=21\right)$. School A students studied only one subject at an advanced level-mechatronics, while each student in School B studied engineering systems as well as one of the following three subjects at an advanced level: computer science, a natural science subject, or mathematics. Data were collected via structured classroom observations, interviews, and a questionnaire. From the analysis of the collected data, we identified 23 engagement structures in total, 12 of which were already known in the literature, and 11 of which were novel. The two groups of students shared nine known structures, and no novel structures. Unlike previous studies of engagement structures, this study was based on an entire year of observations. Additionally, it is one of the first studies of high school student engagement in robotics education. Our findings and conclusions contribute to understanding of student engagement in robotic education, allowing robotics teachers to tailor their instruction more effectively.
\end{abstract}

Keywords Educational robotics · Student engagement · Engagement structures · Technology education $\cdot$ High school students

\section{Introduction}

In recent years, demand for robots has been rising, driven by new developments in automation and computing. This rise in demand has been accompanied by a growing prevalence of robotics education in schools (Anwar et al., 2019). Robotics is

Igor M. Verner

ttrigor@technion.ac.il

1 Faculty of Education in Technology and Science, Technion - Israel Institute of Technology, Haifa, Israel

2 School of Engineering, Massachusetts Institute of Technology, Boston, MA, USA 
considered as an avenue through which students can actively engage in learning concepts from different disciplines (Church et al., 2010; Cross et al., 2015; Korchnoy \& Verner, 2010; Verner \& Hershko, 2003). More than that, the students can develop the skills of adaptability, self-regulation, learning in digital technology environments, and other skills (Ananiadou \& Claro, 2009; Benitti, 2012; National Research Council, 2012) that are vitally needed for learning in the era of the COVID-19 pandemic.

The term student engagement has been used to describe the level of active involvement of students in their learning tasks and activities. Engagement largely determines student-teacher interactions, class atmosphere, and learning outcomes. Research indicates that engagement is positively linked with student's prior academic achievement (Dong et al., 2020; Lee, 2014; Lei et al., 2018; Piñeiro et al., 2019). Fortunately, there are many pathways into robotics that can engage students of different interests and backgrounds (Alimisis, 2013; Rusk et al., 2008). Researchers have observed students performing robotics tasks dedicating extra time to solving robotics problems, as students were trying to find solutions by themselves (You et al., 2006).

\section{Need and rationale for study}

Technology is an optional subject in Israel. About one-third of Israeli high school students choose to study technology subjects. Out of those students, about one-third of those students choose the track that prepares them for academic engineering programs, another third-the track preparing them for technical college, and the remaining third-the track preparing them for working life. The first track is usually open only to students who excel academically, while the latter two tracks do not require high levels of academic achievement (Małgorzata et al., 2018).

Robotics educators adapt the subject for school students of different academic achievement levels. In educating high achieving students, educators emphasise career readiness and twenty-first century skills, while for lower achieving students, robotics serves a tool for experiential learning of STEM concepts (Spolaôr \& Benitti, 2017; Verner \& Revzin, 2017) and for strengthening self-efficacy beliefs (Barak, 2010).

The potential of robotic learning environments for motivating students has been recognized in the literature (e.g., Brown et al., 2013; Hashimoto et al., 2013). However, student engagement in distinct relation to the learning pathways described above has not been investigated. Unlike the present study, our previous studies of student engagement in robotics education did not include multiple long-term observations of student behaviour (Verner, 2013; Verner \& Revzin, 2017). These studies began with the analysis of high achieving middle school students' engagement in an outreach robotics course (Verner, 2013). Then, in the study of learning engagement of low achieving high school students majoring in technology education, we came up with an idea to apply the theory of engagement structures.

The construct of engagement structures was introduced by Goldin et al. (2011) to describe common types of engagement which are triggered by the instant motivational desires of students engaged in learning mathematics. Since its introduction, the construct of engagement structures has been investigated in several studies of learning engagement (e.g., Craft \& Capraro, 2017; Khalil et al., 2019; Perez \& Verner, 2019; Verner \& Revzin, 2017; Verner et al., 2013). 


\section{Research objective and research questions}

The objective of this study was to characterize engagement in high school robotics courses through the lenses of preparation for academic and technical careers. The research questions were:

1. What engagement structures can be identified in high school students studying in a robotics course?

2. What are the commonalities and differences between engagement structures of the two groups of students - those preparing for academic engineering programs and those preparing for technical college?

The rest of this manuscript is structured as follows: first, an overview of the literature on student engagement, learning theories and instructional methods in robotics education is provided. Next, the methods of this study are detailed and explained, followed by its findings. The last is the discussion, where the key findings are elaborated on, the limitations and contribution of the study are described, the implications of this study for robotics education are outlined, and recommendations for educators and for researchers are provided.

\section{Student engagement and robotics education}

This section discusses selected literature on student engagement, engagement structures, the impact of engagement on academic achievement, and student engagement in robotic environments.

\section{Student engagement}

The subject of student engagement has been widely discussed in literature and conceptualized from many different perspectives (Trowler, 2010). In this paper we will mention only those aspects of the subject that are most relevant for our study. Newman defined student engagement as "the student's psychological investment in and effort directed toward learning, understanding, or mastering the knowledge, skills, or crafts that academic work is intended to promote" (Newmann, 1992, p. 12). Behavioural, cognitive, and affective engagement of students in their learning activities largely determines learning outcomes, student-teacher interactions, and class atmosphere (Lei et al., 2018). Student engagement cannot be separated or disentangled from the social context in which it occurs; it is a joint product of his or her motivation and classroom support or thwarting (Reeve, 2012).

\section{Engagement structures}

Goldin et al. (2011) focused on the study of student engagement that can be referred to as an instant emotional reaction on interaction with the teacher, the peers, or the learning environment. The construct of an engagement structure, introduced by them, is intended to describe specific types of student engagement that are typically observed 
in different categories of students and certain learning situations. The authors proposed to identify and determine engagement structures by inductive analysis of student behaviours repeatedly observed during the learning activities.

The construct of an engagement structure includes the following components: the statement of the motivating desire, the scheme of the social interaction, the characteristics of situations which are likely to evoke the desire, and the behavioural patterns being exhibited. The statement of the motivating desire is formulated so, as to represent a certain typical kind of motivating desires that can be observed in different categories of students and in different subjects. The other components of the engagement structure represent motivating desires that are typically observed in a specific category of students learning a specific subject.

Goldin et al. used engagement structures to characterise student engagement in urban middle school mathematics classrooms. Furthermore, the authors proposed a general approach on how to investigate engagement and called to identify and determine engagement structures in different learning activities. Verner et al. (2013) applied the construct of engagement structures to the study of engagement in an ethno-mathematically based teacher education course. They observed some of the engagement structures described by Goldin et al. (2011) and identified a new structure related to cultural identity of students. Verner and Revzin (2017) applied the theory for the study of engagement in an automated chemistry laboratory course. The study indicated the presence of some of the engagement structures found by Goldin et al. and discovered three new structures specific to the category of learners and type of learning environment.

The engagement structures found in the studies mentioned above are summarized in Table 1.

\section{Engagement and achievement}

Engagement has been positively linked to student academic achievement (Lee, 2014). For example, Wu and Huang (2007) investigated 9th-grade cognitive, emotional, and behavioural engagement in teacher-centred and student-centred technology-enhanced classrooms. The authors reported that low-achieving students in the student-centred group learning demonstrated disengaged behaviours and participated in few conceptual discussions. This low-level engagement seemed to have a negative impact on their learning achievements. The findings suggest that there is no universal instructional approach suitable for engaging every student.

Previous studies have found that lower achieving students tend to exhibit less engagement with learning than higher achieving students (Jensen 2013) and that student perception of the school environment affects their academic motivation and engagement (AlonsoNuez et al., 2020). Students on vocational tracks tend to be lower achievers than students who excel academically (Kelly \& Price, 2009).

Self-determination theory assumes that all students possess inherent growth needs that provide a motivational foundation for their high-quality classroom engagement and positive school functioning. This theory emphasizes the instructional task of vitalizing students' inner motivational resources as the key step in facilitating high-quality engagement. It identifies the inner motivational resources that all students possess, and offers recommendations as to how teachers can mobilize, nurture, and vitalize these resources during the instruction to facilitate high-quality student engagement (Reeve, 2012). 
Table 1 Engagement structures

\begin{tabular}{|c|c|}
\hline Engagement structure & Description \\
\hline Acknowledge my culture ${ }^{\mathrm{a}}$ & $\begin{array}{l}\text { The motivating desire is rooted in cultural diversity of the class and awakes } \\
\text { when the student feels personally involved and urged to represent his or her } \\
\text { own culture }\end{array}$ \\
\hline Check this out ${ }^{\mathrm{b}}$ & The motivating desire is to get a payoff or benefit \\
\hline Don't disrespect me $\mathrm{e}^{\mathrm{c}}$ & $\begin{array}{l}\text { The desire emerges when meeting a perceived threat to the student's dignity, } \\
\text { status, or self-respect }\end{array}$ \\
\hline Don't want to learn it ${ }^{\mathrm{d}}$ & Students' reluctance to perform learning assignments imposed against their will \\
\hline Get the job done ${ }^{b}$ & $\begin{array}{l}\text { The student's motivating desire is to satisfy a sense of obligation to complete an } \\
\text { assigned task to follow the given instructions correctly }\end{array}$ \\
\hline I'll do something else ${ }^{\mathrm{d}}$ & $\begin{array}{l}\text { The student's motivation desire is to substitute a given assignment by a person- } \\
\text { ally meaningful one, without compromising the difficulty }\end{array}$ \\
\hline I'm really into this ${ }^{c}$ & Here the desire emerges when the student is excited by the learning activity \\
\hline It's interesting to discuss ${ }^{\mathrm{d}}$ & The students find the learning experience interesting and wish to discuss it \\
\hline It's not fair & $\begin{array}{l}\text { The motivating desire emerges when the student feels hurt because his/her par- } \\
\text { ticipation in a learning activity is not recognized by the class or by the teacher }\end{array}$ \\
\hline Let me teach you ${ }^{b}$ & $\begin{array}{l}\text { The student desires to help a classmate who faces difficulties in performing } \\
\text { learning tasks }\end{array}$ \\
\hline Look how smart I am ${ }^{b}$ & $\begin{array}{l}\text { The motivating desire is to impress classmates and achieve positive self-regard } \\
\text { by demonstrating the ability, knowledge, and intelligence }\end{array}$ \\
\hline Pseudo-engagement ${ }^{\mathrm{c}}$ & $\begin{array}{l}\text { The desire is to look good to the teacher or to peers by seeming to be engaged. } \\
\text { It is appearing to be engaged but, it is not engagement }\end{array}$ \\
\hline Stay out of trouble $e^{\mathrm{e}}$ & $\begin{array}{l}\text { The student desires to avoid interactions that may cause conflict or trouble and } \\
\text { therefore tends to withdraw from sharing ideas and feelings with the class }\end{array}$ \\
\hline
\end{tabular}

\footnotetext{
${ }^{\mathrm{a}}$ Verner et al. (2013)

${ }^{\mathrm{b}}$ Goldin et al. (2011), Verner et al. (2013), Verner and Revzin (2017)

${ }^{\mathrm{c}}$ Goldin et al. (2011), Verner and Revzin (2017)

${ }^{\mathrm{d}}$ Verner and Revzin (2017)

${ }^{\mathrm{e}}$ Goldin et al. (2011)
}

\section{Learning engagement in robotic environments}

One of the most important duties of a teacher is to offer students opportunities for handson exploration and to provide tools to construct knowledge (Alimisis, 2013). This knowledge construction can happen most effectively in a context where the student is engaged in constructing a technological artefact (Papert, 1980). The wide range of robotics applications can engage students with different interests and from various backgrounds (Alimisis, 2013; Rusk et al., 2008). One of the reasons behind the apparent improvements in student engagement when learning with robots is that robots are especially appealing to students due to their physical form and novelty (Kaburlasos \& Vrochidou, 2019).

Learning with robots can benefit students of different academic levels. Collaborative learning in robotic environments can benefit high achieving students by developing their teamwork skills, which are essential for the current workforce (Ananiadou \& Claro, 2009; Korchnoy \& Verner, 2010; National Research Council, 2012; Verner \& Hershko, 2003). For lower achieving students the hands-on interdisciplinary activities with robots provide an effective way to learn STEM concepts and acquire technical skills (Cuperman \& Verner, 2013; Spolaôr \& Benitti, 2017). 
Brown et al. (2013) applied behavioural strategies for engagement using robotic educational agents. In the study, the authors focused on a testing scenario to evaluate the role and efficacy of engagement using a robotic agent. In order to enable human interaction, the robot was programmed with a range of verbal and nonverbal behaviours. The authors reported that the approach effectively eliminates idle time and keeps the student engaged in the allocated tasks.

Verner and Revzin (2017) proposed an educational approach in which high school students majoring in mechanical engineering will be involved in the development of robotic laboratory devices and use them for chemical experiments. The authors observed learning activities at different stages of the course and characterized students' engagement structures throughout these stages. They concluded that engagement structures can evolve and do not have to remain fixed within students.

\section{Method}

In this section we explain the research methodology and describe setting of the study and participant sample. Next, we give a detailed description of the robotics courses followed up in this study, the instruments of data collection, and the analyses of collected data. Finally, we outline how ethical standards were upheld for the study.

\section{Research methodology}

Technology education is a broad field which includes various disciplines and engages different categories of students. This high level of variance presents challenges for studying learner engagement from a general perspective, even in just one discipline such as robotics education. Taking this breadth and diversity into consideration, the research methodology chosen for this study can be best described as multiple case studies, in which data about a highly context-dependent phenomenon is collected from multiple cases (Creswell et al., 2007). This study investigates two groups of students in the high school mechanical engineering track: one group from a program meant to prepare students for technical careers, and another group in a program meant to prepare students for academic studies in engineering. Thusly, the present study covers two ends of the spectrum in high school robotics education, providing a broader perspective of the phenomenon under investigation than in the case of a single case study.

In Israel robotics is taught in schools in different ways, making valid quantitative comparisons between different schools difficult. Even in one robotics class, the diversity of experiential activities and the difficulty to quantitatively analyse students' engagement led us to opt for using a qualitative approach. More specifically, the researchers employed engagement structures as a theoretical framework and applied a theory-driven, top-down approach (Braun and Clarke, 2006) for analysing the collected data. Previous empirical studies on engagement structures have also opted for a qualitative approach (e.g., Verner et al., 2013).

\section{Research setting}

The study took place at two locations in Haifa, a city in the north of Israel. The first location was in the Technology Laboratory of the University Faculty of Education in Science 
and Technology. The second location of the study was at an urban comprehensive private school. In each location, a different group of high school students was taught a robotics course by their respective teacher. The curricula were different, but both ground on design and inquiry activities with robots.

School A is an urban public school. Due to a recent change of location and some funding challenges, it had no laboratory facilities. The University afforded the school with the opportunity to conduct the robotics course at the Technology Laboratory of the University.

School B is an urban private comprehensive school. Recently, the school opened an elective program for high school technology in robotics and engineering systems. Lessons in this program are conducted in the school's own technology laboratory and two classrooms.

\section{Research sample}

Students who participated in this study $(\mathrm{N}=41)$ belonged to one of two schools: School A or School B. School A students $\left(n_{1}=20\right)$ were all 11 th graders -12 girls and eight boys, studying robotics as part of high school mechatronics track, with the specific aim of providing students with the necessary background in science and technology required for technician studies following their high school graduation. most of the students in the School A group were not accepted into more prestigious high school tracks, such as computer science or natural sciences. The teacher of this class was a veteran physics teacher and Ph.D. holder with research and practical experience in teaching students who are not high achievers in science and technology. He was tasked by the school to design and teach a robotics course specifically for the students in question.

School B students $\left(\mathrm{n}_{2}=21\right)$ were all 11th graders-19 boys and two girls. All of them were matriculating in computer science, a natural science subject, or mathematics. Recently, the school established an elective robotics and engineering systems program for high school students, with the specific aim of preparing students for academic studies in engineering. School B students who participated in this study were taught by an engineering teacher with extensive professional experience in the hi-tech industry.

\section{The courses}

While both courses-in School A and in School B-centred on experiential learning, design and inquiry in robotic environments, the overall aim of each course was different: in the case of the course taught to School A's students, the overall aim was to teach them basic scientific concepts through experimentation with robots, while in the case of the course taught to School B, the overall aim was to teach students how to solve real-life problems by designing and building robots. The students in School B had already learned the basics of robotics in the 10th grade, and therefore did not need to learn this as the students in School A did.

\section{School A}

The objectives of the course were to (1) know the principles of motor operation, mechanical transmissions, sensors, and open- and closed-loop control, (2) understand the scientific and mathematical concepts involved in the design and operation of robotic models, (3) acquire basic skills in design and analysis of robotic models, and (4) acquire basic skills of 
scientific experimentation. Learning activities revolved around several assignments that the students performed individually or in pairs. In addition, the students executed three robotics projects. These projects tied back to the overall aim of the course, which was to teach students basic scientific concepts through robots.

The course progression was as follows: (1) presenting a physical concept to students, (2) guiding students in planning of experiment, (3) teaching students the relevant concepts and analysis tools, (4) guiding students in conducting experiment and collecting data, (5) guiding students in analyzing collected data, (6) guiding students in preparing the assignment report, and (7) guiding students in presentation of the assignment.

When performing the assignments, the students used different technological tools. They constructed robots from the Lego Mindstorms EV3 kits and 3D printed the needed additional parts using the MakerBot Replicator (Fig. 1A). The students programmed robots with MindStorms software. In physical experiments, they collected and processed data from robot sensors by means of Fourier's Data Logger (Fig. 1B).

\section{School B}

The objectives of the School B group course were to (1) understand the principles of robot motion and control, (2) acquire basic skills of robot construction, programming, and operation, (3) acquire basic skills of 3D design and printing, (4) develop applied problem-solving skills.

The course progression was as follows: (1) learning fundamental concepts in robotics and applying them, (2) designing and implementing a given electronics-based project, (3) designing and implementing a robotics solution to a challenge posed by a commercial company, and (4) redesigning part of the classroom to introduce a robotics component, e.g., a smart screen. Throughout the semester, students were introduced to technological innovations and were taught ad-hoc topics that the teacher deemed as required for strengthening their proficiency as designers and implementors of robotic projects.

The students used a wide set of technological tools. They constructed robots from the Lego Mindstorms EV3 kits. The Arduino Uno and Raspberry Pi controllers were used for programming robot behaviours, remote control, and statistical analysis. The students designed the needed additional parts with SolidWorks and produced them in plastic using TierTime 3D printer or in wood and metal using CNC, grinding, and drilling machines. Figure 2 shows images of students while carrying out project activities.
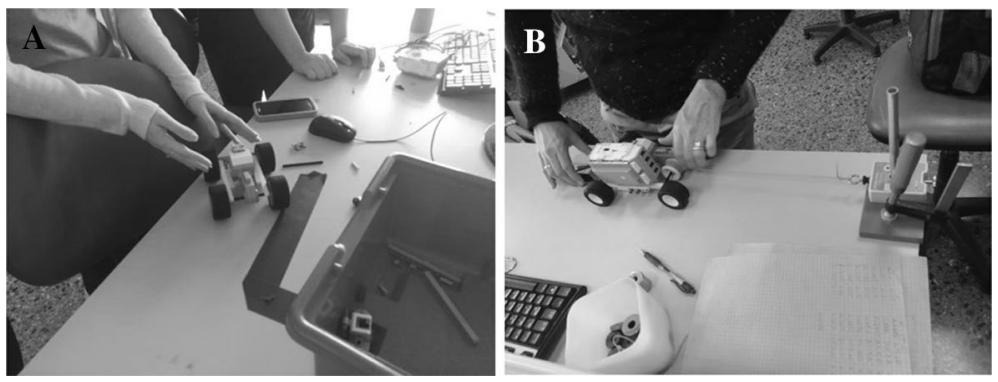

Fig. 1 Students from School A at work: A Robot construction; B Making an experiment 

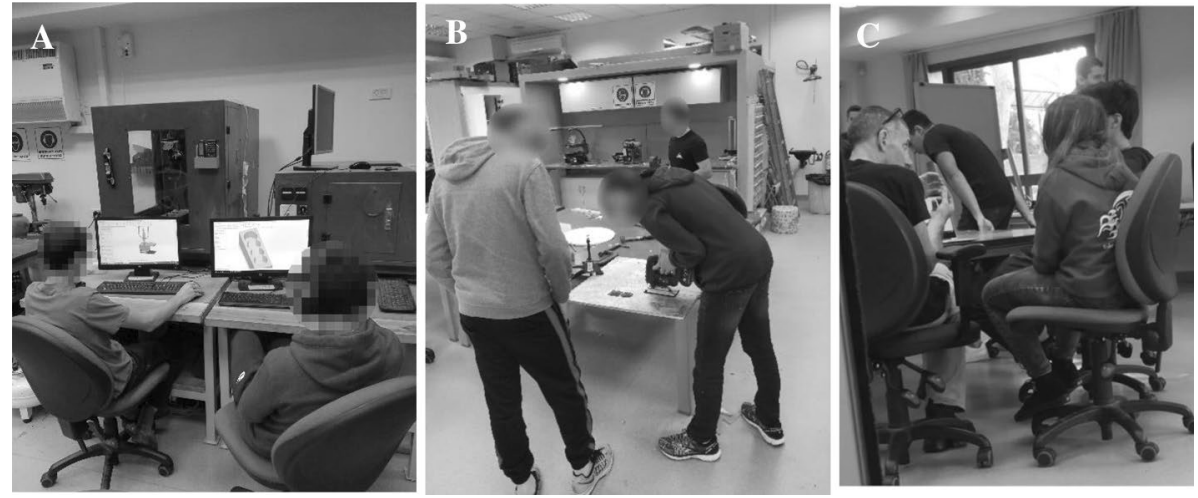

Fig. 2 School B students at work on robot projects: A Design; B Construction; C Guidance

\section{Data collection and analysis}

Data collection was carried out over the entire school year, resulting in frequent, long-term observations of student behaviours. Data were collected by the second author, who acted as an observer in the classrooms. Importantly, he was not involved in the design or teaching of any of the course curricula.

For each of the two student groups, data were collected thusly: throughout each lesson, indications of engagement in robotics activities were identified and recorded in the observation protocol. This protocol was developed by two of the co-authors based on Hatch (2002). The observation protocol form included the following data: date, participating students, lesson topic, lesson objective, project assignment, lesson assignments, learned concepts, problems solved by the students, teacher's interaction with the students, notable episodes of student engagement. At the end of each lesson, the in-class observer discussed the observations made during that lesson with the teacher, thus supplementing them with the teacher's interpretation of the collected data. At the end of the course, a questionnaire was deployed among individual students, followed by individual student interviews, both intended for verifying and supplementing previously collected data.

Data analysis was carried out in the following way. We selected from among the noticed episodes of student engagement those pertaining to each engagement structure known from the literature and used the episodes to characterize the structure in the considered context. Then, we analysed the episodes that did not match the known engagement structures. We selected episodes that reflected a certain common pattern of learning engagement and formulated an engagement structure that expressed the pattern. In formulating engagement structures, we followed the recommendations of Goldin et al. (2011).

The researchers involved the respective teacher of each participant group in the analysis. The teacher's point of view is naturally important, since they are familiar with students' behaviour and can also provide context for it based on their familiarity with their students.

Based on the observations recorded by the in-class observer, the authors held regular meetings in which they discussed episodes of the learning process that provided evidence of engagement or disengagement were discerned, and subsequently analysed those episodes to determine patterns of learning engagement. For each pattern, they first examined whether it fits one of the engagement structures already described in the 
literature (see Table 1); in cases where they could not identify any such structure, they tried to ascertain whether a novel engagement structure can be described. The discussion with the teacher at the end of each lesson concerned the patterns of engagement observed by both the teacher and researcher, with the teacher often providing the interviewer with explanations pertaining to student intentions and possible reasons behind their behaviour.

The engagement structures identified using the observation protocol and teacher interviews were verified and supplemented using a questionnaire (see Appendix), which was deployed to individual students following the end of the course, after the final course grade was provided to all the students. The questionnaire included open-ended questions intended to gather data on engagement structures already known and found in the existing literature, whether these were already identified using the previous tools or not. Each item in the questionnaire pertained to one distinct engagement structure.

Finally, the engagement structures that were identified using the previously collected data, whether already known or newly discovered, were verified and supplemented with further data concerning internal factors of engagement-such as desires and beliefs-by conducting an open-ended interview with each student. Green et al., (2012) noted that the advantage of an open-ended interview is that it allows extending and clarifying the informant's responses through probing.

\section{Study ethics}

Ethical clearance and permissions for the study were obtained from the University Behavioural Sciences Research Ethics Committee and from the Ministry of Education Office of the Chief Scientist. The goal and method of our study was explained to the participating students in advance, and they each were told explicitly that they had the right to cease their participation and exit the study with no explanation or ramifications. Participants' identities were kept anonymous. In-class observations were made with the consent of the schools' teachers and with the permission of the schools' respective principals. Participating students and their legal guardians signed A letter of consent to participate in the research. Due to Ministry of Education guidelines for research studies, we were not able to obtain students' grades.

\section{Findings}

This section gives an account of the engagement structures which the researchers had identified in students, based on the collected and analysed data. The section is divided into three sub-sections: first, we discuss and illustrate by examples the engagement structures that are described in literature and identified in our study; second, we present novel engagement structures not mentioned in literature (to the best of the authors' knowledge); and third, we compare the engagement structures identified in the two groups to indicate the differences in their learning engagement.

Throughout this section, participant codes are used instead of names; each code starts with a letter denoting the group, and a number denoting the student in the list of participants. For example: A03 is a student \#3 in the list of students from School A. 


\section{Existing engagement structures}

The researchers identified 12 engagement structures already described in the literature (see Table 1) and indicated in our study. Three out of these structures were observed in one of the groups, with the rest identified in both groups. Due to restrictions by the Israel Ministry of Education, student names could not be taken in the questionnaire, and thus could not be identified.

Table 2 presents these engagement structures with representative quotes from the interviews given by students from the groups where the structures were identifiedNovel engagement structures

The researchers identified 11 engagement structures which they did not find in the literature. Interestingly, not one of these novel structures was common to both groups of students: six novel structures listed in Table 3 were identified in the School A group.

The five novel structures identified in the School B group are presented in Table 4.

The following are detailed descriptions of the novel engagement structures the researchers had identified in the School A group.

\section{Explain in my native language}

As repeatedly observed during the course, the students of the School A group experienced difficulties in understanding the concepts taught by the teacher in Hebrew. They expressed confusion, especially when the teacher used higher vocabulary. When the teacher, wishing to help the students, switched to Russian, they rejoiced and more deeply engaged in learning.

\section{I learn with my body}

The researchers observed episodes when the students were especially engaged in learning when it involved bodily experiences to examine physics concepts and ideas. This typically happened at the stage when the students learned concepts and analysed tools to be applied in the robotic assignments. For instance, A17-a female student-and two other students [A16, A18] had difficulties in understanding some physics concepts, so the teacher let the students examine these concepts through bodily experiences. In one of the lessons, A17 and the other two students found it hard to learn the concept of the centre of gravity (COG). The teacher asked the students to sit in a chair with their back against the chair and their feet on the floor. Then he asked the students to try to stand up with their back straight. After the students tried unsuccessfully, he explained why this did not work in terms of COG. The students smiled and expressed that after those experiences, they understood the concept. From there, they were engaged in the assignment for the rest of the lesson.

Based on the interview comments, for these students, it was very important to include this kind of activity in their learning process. The teacher noted that he found the effectiveness of such kind of group activities for these students.

\section{Let me learn on my own}

The observations showed that some students were engaged in the learning activities only when they worked alone; for example, A12, a male student who showed low 
Table 2 Known engagement structures identified in both groups

\begin{tabular}{|c|c|}
\hline Engagement structure & Student quote \\
\hline heck this out ${ }^{\mathrm{a}}$ & $\begin{array}{l}\text { I'm not a big fan of robotics, but I know the course activities can help me to pass the } \\
\text { matriculation exam. Many of my friends took the course and passed the test. [A18] } \\
\text { This course is helpful to enter the University. I'm sure I will enter if I have this } \\
\text { course in my record. [B08] }\end{array}$ \\
\hline Don't disrespect me $\mathrm{a}^{\mathrm{a}}$ & $\begin{array}{l}\text { The teacher said that my answer was wrong. I felt from his way to say that he thinks } \\
\text { I know nothing about math. I don't have the best score in math, but have some } \\
\text { knowledge of the subject. }\left[\mathrm{A}^{1}\right]\end{array}$ \\
\hline Get the job done ${ }^{a}$ & $\begin{array}{l}\text { The student skipped the question and just said: "you know, I just want to do what I } \\
\text { need to do.” [A10] } \\
\text { I was so stressed to finish the project on time and for my peers, they don't care } \\
\text { about, or I couldn't persuade them for help me. I needed them, they are from other } \\
\text { subjects [in high school] which are not easy for me. [B09] }\end{array}$ \\
\hline I don't want to learn it ${ }^{\mathrm{b}}$ & $\begin{array}{l}\text { "I entered the course because some friends told it is easy, no test. But no one men- } \\
\text { tioned that there are presentations. It is hard. The teacher needs to find an option } \\
\text { for me." [A19] }\end{array}$ \\
\hline I'll do something else ${ }^{a}$ & $\begin{array}{l}\text { The assignment was hard for me because it was based mainly on physics. I asked } \\
\text { the teacher to change the assignment and include materials in chemistry to make it } \\
\text { more interesting. He agreed and helped me to change the assignment. }\left[\mathrm{A}^{1}\right] \\
\text { I do it when I don't find the assignment interesting. I didn't have a problem to } \\
\text { change the assignment because the assignment I did was at the same level. The } \\
\left.\text { teacher evaluated my other assignment. [ } \mathrm{B}^{1}\right]\end{array}$ \\
\hline I'm really into this ${ }^{\mathrm{a}}$ & $\begin{array}{l}\text { Before this course, I used to see science and mathematics like something that only } \\
\text { exists on the whiteboard and lives in the teacher's head. However, by working with } \\
\text { these robots, I saw how science and mathematics help to make great things. [A09] } \\
\text { During the physics, and mathematical lessons I saw some things we might use in } \\
\text { engineering. But In this lesson, we really work as engineers, I love to be here. } \\
\text { [B11] }\end{array}$ \\
\hline It's interesting to discuss $\mathrm{s}^{\mathrm{a}}$ & $\begin{array}{l}\text { Yes, it's true from the day I couldn't answer. I was more involved in the experiments } \\
\text { and now I feel I want to know more and discuss about it. [A01] } \\
\text { Discuss with others is something that can help to better understand, because I can } \\
\text { see other points of view and extract the truth by comparison. [B15] }\end{array}$ \\
\hline It's not fair ${ }^{\mathrm{a}}$ & $\begin{array}{l}\text { The teacher focused only on my peer, but I also contributed to the task. He wasn't } \\
\text { aware that I'm a good student too. [A02] } \\
\text { When I submit a task, the teacher gives a high or bad grade. I think if my homework } \\
\text { is not so good, he could give a medium grade and appreciate my effort. [B14] }\end{array}$ \\
\hline Let me teach you ${ }^{a}$ & $\begin{array}{l}\text { I have no problem to help peers if the teacher asks. I didn't do it by my own because } \\
\text { I was busy with my experiment and had no time to see if someone needs help. } \\
\text { [A01] } \\
\text { If I know something, I like to help peers, it's reasonable. [B16] }\end{array}$ \\
\hline Look how smart I am ${ }^{c}$ & You will see amazing things that I'll do. [B01] \\
\hline Psuedo-engagement ${ }^{\mathrm{a}}$ & $\begin{array}{l}\text { The student A05 denied the facts that the researcher had observed } \\
\text { If I would not show that I am engaged, the teacher would give me a bad grade. }\left[\mathrm{B}^{1}\right]\end{array}$ \\
\hline Stay out of trouble ${ }^{a}$ & $\begin{array}{l}\text { The teacher is so smart, and it scared me. [A11] } \\
\text { I preferred not to participate in decision making [and did so] only in few cases, } \\
\text { because it didn't interest me or was not in my specialization. [B20] }\end{array}$ \\
\hline
\end{tabular}

\footnotetext{
${ }^{a}$ Engagement structures identified in students of both groups

${ }^{b}$ Engagement structures identified in students of Group A

${ }^{\mathrm{c}}$ Engagement structures identified in students of Group B
} 
Table 3 Novel engagement structures identified in School A group

\begin{tabular}{|c|c|}
\hline Engagement structure & Student quote \\
\hline Explain in my native language & I don't understand. Please explain in Russian* \\
\hline I learn with my body & $\begin{array}{l}\text { For us [A16, A17, A18] it was amazing, we have never understood a } \\
\text { physics concept so easy. So, maybe we need activities with the body to } \\
\text { understand concepts. [A17] }\end{array}$ \\
\hline Let me learn on my own & $\begin{array}{l}\text { I haven't noticed it before, but now when you asked, I realize that I work } \\
\text { better without my friend, he talks too much. [A12] }\end{array}$ \\
\hline Please teach me & $\begin{array}{l}\text { We }[\mathrm{A} 13, \mathrm{~A} 14] \text { need the teacher, when the teacher is with us, we feel } \\
\text { confident and we know if there is some problem or we don't understand } \\
\text { something, he will help us. If he is not with us, we are afraid to break } \\
\text { something or misunderstand something without his help? [A13] }\end{array}$ \\
\hline This is hard for me & $\begin{array}{l}\text { I'm just } 3 \text { points in mathematics and I'm not able to calculate a slope in a } \\
\text { graph. These activities are too hard for my level. [A11] }\end{array}$ \\
\hline This is boring & $\begin{array}{l}\text { I don't see the point to do always similar robotics projects, I know how to } \\
\text { do one, so I know how to do all. [A20] }\end{array}$ \\
\hline
\end{tabular}

*The authors do not have the student ID on file

Table 4 Novel engagement structures identified in School B group

\begin{tabular}{|c|c|}
\hline Engagement structure & Student quote \\
\hline I am doing this only if it is fun & $\begin{array}{l}\text { I'm good in physics, but it's always so theoretical. Here I build } \\
\text { nice things and we with my friends have fun. The problem is that } \\
\text { sometimes the teacher wants us to focus only on the project and } \\
\text { application of physics. [B07] }\end{array}$ \\
\hline I am just an assistant & $\begin{array}{l}\text { Sometimes I feel I'm good in helping my peers in how to present the } \\
\text { project and how to organize the information. [B04] }\end{array}$ \\
\hline I do not like being corrected & $\begin{array}{l}\text { I know I'm right, but for other people (the teacher) there is always } \\
\text { something wrong in my work. [B06] }\end{array}$ \\
\hline I will make my dreams come true & $\begin{array}{l}\text { In computer science it's always about algorithms and programming. } \\
\text { Here I can build things. I want to be a pilot and it's good for me to } \\
\text { build robotics things. [B16] }\end{array}$ \\
\hline My way or no way at all & $\begin{array}{l}\text { I don't feel comfortable to follow what others said. I know I'm smart } \\
\text { and I want to create my own way. [B12] }\end{array}$ \\
\hline
\end{tabular}

levels of engagement in the beginning of the course. A12's classmate [A15] distracted him from learning by talking about topics unrelated to the learning activity. In one of the lessons, [A15] was absent, and A12 worked alone. He was observed in this lesson to be closely engaged in the assignment and performed it well. Since then, with the consent of A12, the teacher has let him work alone and perform assignments individually. The teacher commented that he repeatedly observed this learning behaviour. His solution was to reorganize the teams and let such students work alone. In the interview, A12 said that before the interview, he did not pay attention to this fact, but when the researcher asked him about it, he realized that he worked better when he worked alone. 


\section{Please teach me}

The researchers observed episodes when the students were not confident in performing the assignment and only worked under the teacher's guidance. For instance, A14 was a female student who wanted neither to work alone nor with a teammate, but only when the teacher tutored her personally. Sometimes, the teacher did not help her much, but his presence made the student feel confident in performing the task. This observation was supported by the comments that the student gave in the interview.

The teacher commented that from his experience, this behaviour was quite typical in the first stage of the course. In his opinion, it is essential to provide such students with individual guidance. Therefore, he recommended involving a second teacher or at least a teacher's assistant in the class. Even if the group only numbers 12 students, the attention they demand is beyond what can be provided by one teacher.

\section{This is hard for me}

Some students claimed that they did not have the background knowledge needed to perform the assignment. For example, in one instance when the teacher explained the task to A11, a female student, she just drew a Cartesian plane in her notebook and claimed that she was unable to perform this task. She said that she lacked the knowledge and skills in mathematics and physics needed for the task. We repeatedly observed this type of behaviour in this student during the course. The teacher's strategy was to strengthen the student's confidence. In the beginning, he gave her simple tasks with full support. Then, each lesson, the teacher gave her less support, increased the complexity level of the tasks, and assigned more responsibility to the student. At the end of the year, the student was able to carry out the project with little support and presented it to the class. It was a significant achievement considering that at the beginning of the course, she claimed she was not even able to construct a simple robotic model.

The teacher noted that nurturing of student's self-confidence is a long-term process. In the above example this process took eleven months for the student to achieve some level of self-confidence and self-dependence.

\section{This is boring}

We observed students who refused to train the skill by exercising it. For example, A20 was a male student who complained that the core of the assignments always was the same. The point is that when the teacher asked the student to do a new task using the skills that were acquired through the "boring" activities, he showed a lack of the skills and simply did not know what to do. The teacher's strategy was to let the student see the value of knowledge and skills learned in the course and the importance of training through exercise and through practical activities. This observation was supported by the comments that A20 gave in the interview, where he reinforced the fact that he did the same and it was boring for him.

The teacher commented that it is typical for some students in this category to claim that they "already know everything," but in fact, when the teacher asked them to perform a task, sometimes these students did not know what to do. Therefore, in the 
teacher's opinion, it is crucial to engage such students in experiential learning, which includes training by exercise.

Below are detailed descriptions of the novel engagement structures identified in the School B group.

\section{I'm doing this only while it's fun}

From the observations, there were episodes in which students were engaged in learning assignments when they considered them as play activities. For instance, B07 was a male student who perceived the project as a game to be played. He became interested when the task was to build something for the robotic model. At some point, he stopped working and became disengaged with the learning activity. He explained to the researcher that he enjoyed the activity but did not want to spend the entire lesson on it, as it would not be fun. He did not show interest in programming and theoretical lessons, but he liked the electronics activities. He said that in other subjects like physics, he just solved problems and learned theoretical topics; on the other hand, when learning engineering systems, he built interesting things and applied everything he saw in the physics class. So, he enjoyed the lessons, and thought they were fun.

The teacher said that he could not understand this student. The student always said he liked the course, and that he felt excited about the projects. However, the teacher had to attract his attention continually and the student always asked what to do next, even if the teacher already explained the assignment. The teacher commented that on one hand, the student claimed that he was excited, but on the other hand, he always needed someone to push him back to performing the assignment.

\section{I am just an assistant}

We observed students who were deeply engaged in the projects but did not performed, by themselves, hands on activities of robot construction and programming. These students only assisted to their teammates. If the teacher required them to program a sensor or develop part of the mechanism in the robotic projects, they didn't like it and became disengaged. For instance, B04 - a male student - avoided getting involved in hands on activities. He liked to support his classmates by painting, writing project-related texts, designing the poster and the slides for the presentation, etc. If peers asked B04 to help in construction or programming, then he agreed and engaged in the activity. It was difficult to engage him in learning in any other way.

The teacher commented that this episode shows his difficulties in teaching the student who did not want to learn robotics but did want to assist his classmates. The teacher also commented that he knew B04's parents and they had pressured B04 to join the course as it gives bonus points to enter the University. Another reason to join the course was that B04's friends had also taken it and B04 wanted to be with them. The teacher was aware that the student used to do things less related to the project and acted as an assistant without getting involved in the task. He confessed that sometimes allowed B04 to perform activities such as designing a poster, which was not exactly part of the course's curriculum. However, it was the only way the teacher could keep him engaged in the course's activities. In the teacher's opinion, the student was not happy with the course. 


\section{I don't like being corrected}

We identified episodes in which students were engaged in the assignment, but when the teacher pointed out mistakes in their work, the students reacted negatively to the comments, felt offended, and in consequence turned to disengage for a period from one hour up to the rest of the lesson. For example, B06 was a male student who was deeply engaged in the projects. However, when the teacher looked at his work and found errors, the student became frustrated and upset. B06 stopped working on the project and turned to web surfing and talking with peers on topics unconnected to the assignment. He was disengaged for quite a long time and only returned to work on the project at the end of the lesson. Such episodes were repeatedly observed during the course.

The teacher noted that students of this category are accustomed to achieving high grades and receiving praise at school and in their home. Therefore, some of them could feel offended when the teacher pointed out the errors they made. The teacher explained that some of these students felt that teacher's comments about their mistakes can cast doubt on their status of smart students.

\section{I will make my dreams come true}

We observed students who showed deep engagement and concentration on the task and who were driven by the desire to achieve their long-term goals. For example, B16was a male student who showed exceptional engagement and concentration during the projects. In the theoretical part, he asked questions to be sure he understood everything. In the practical lessons, he tried to dedicate extra time to the project and always wanted to go a step further than the rest of the students. He helped students who asked for it but rejected attempts to distract him from the learning. On his own initiative, B16 changed one of his major subjects from computer science to engineering systems. His concentration on and level of immersion in the task were outstanding. He did not express excitement but looked motivated and immersed in the assignments. The level of his learning engagement was higher than that described in literature by the engagement structure "I'm really into this".

The teacher commented that this student was one of the best students in the group. The teacher knew that the student was good in computer science, and he was honoured to accept him in the group when B16 asked his permission. The teacher said this student was outstanding in his group for his creativity and the level of learning engagement. The teacher also noted the student was very interested in the subject because he decided to join the engineering systems course even though in computer science, he would receive a higher bonus. Moreover, the teacher commented that one of the reasons for this learning behaviour was that his parents instilled him the desire to learn and strongly influenced his excellent behaviour.

In the interview, the student explained that he moved from computer science to engineering systems because in computer science, it was no chance to build something with a $3 \mathrm{D}$ printer, actuators, etc. While in engineering systems, he has this chance as well as the opportunity of programming system controllers. Regarding his learning behaviour, B16 explained that he behaved the same way in all the subjects and wanted to be successful in all his learning activities. Also, at home, his parents taught him to respect and value the teacher's work by respecting the teacher and do his best on each assignment. The students said he wanted to be a pilot in the future. 


\section{My way or no way at all}

The researchers observed episodes when the students were only engaged when they solved problems and carried out tasks in their own way. If that worked, they continued to be engaged in the task; but if not, they stopped and became disengaged. For instance, B12 was a male student who had worked on a project and who had always dedicated a great amount of time to his assignments. However, the current project had to be developed in his way. If he faced a problem, he tried to find a solution on the Internet. If he could not find the solution, he looked for a peer who could help him. If he did not get help from peers he became disengaged and started to talk with friends and play games on the Internet. Similar cases were found in other students.

The teacher commented that through his experiences he has realized that some of the students are accustomed to certain learning strategies, and their success and failure in applying these strategies largely determines their learning engagement. The teacher noticed that he experienced difficulties in trying to change their learning strategies.

\section{Discussion}

This section begins with a summary of our findings, directly addressing our research questions. We continue by discussing the engagement structures we had identified in relation to existing literature on student engagement, technology education, and learning with robots. We end with implications of our findings to robotics education, recommendations for educators and researchers, and a summary of the contribution of this study.

\section{Summary of findings}

The first research question was: 'What engagement structures can be identified in high school students studying in a robotics course?' In response to this question, we observed that our research sample $(\mathrm{N}=41)$ exhibited 23 engagement structures in total, 12 of which were already known and existed in the literature, and 11 of which were novel (see Tables 2, 3, 4 for details). Previous studies that investigated engagement structures in other disciplines had also identified novel structures (Goldin, 2018; Perez \& Verner, 2019; Verner \& Revzin, 2017; Verner et al., 2013).

The second research question was 'what are the commonalities and differences between engagement structures of the two groups of students-those preparing for academic engineering programs and those preparing for technical college?' In response to this question, we observed that School A group $\left(\mathrm{n}_{1}=20\right)$ exhibited 17 engagement structures, and that School B group $\left(n_{2}=21\right)$ exhibited 15 structures. The two groups shared nine known structures, but no novel structures: the six novel structures identified in School A group were not observed in School B group, and the five novel structures identified in School B group were not observed in School A group. We identified all the engagement structures that had appeared in the literature. See Tables 2, 3 and 4 for details.

We identified three known engagement structures that differentiated between the two groups, namely 'Don't disrespect me' and 'I don't want to learn it' (School A group), and 'Look how smart I am' (School B group). Moreover, the two groups of students did not share any novel structures with each other; while School A group's novel structures centred 
around their difficulties with learning the topic at hand, School B group's novel structures centred around taking charge, or wanting to take charge of their own learning. These structures represent different perceptions of the learning experience and of oneself as a learner, similar to those we found for the known structures which the two groups did not share.

The distinction we found in engagement structures-both novel and previously reported - between the two groups warrants explanation. In our opinion, this distinction is rooted in the significant differences in prior academic achievement between the two groups of students. We did not have access to the data on the students' achievements, and our inference about these differences is based on the evaluation of their prior knowledge given by the teachers. The situation, in which the academic performance of school students in technical tracks is lower than that in academic tracks, is quite typical (Małgorzata et al., 2018). Since, as known (Dong et al., 2020; Lee, 2014; Lei et al., 2018; Piñeiro et al., 2019) that student academic achievement and learning engagement are in direct relationship, we explain the observed differences in learning engagement in the two robotics courses by the differences in the level of students' prior academic achievement in the two groups.

Related to this explanation, Wu and Huang (2007) reported that students who were low achievers tended to be disengaged when compared with high achieving students, when the instructional method was student-centred. Their findings corroborated our characterization of the novel engagement structures we found in both study groups. The high achievers expressed wanting to direct their own study ('Look how smart I am'), whereas students in the lower achieving group expressed desire for further instructional support from the teacher. In the specific case of learning with robots, a potential compounding factor for low achieving students' disengagement ('Don't disrespect me', 'I don't want to learn it') could be their difficulties in learning the new subject through the experiential learning cycle (Verner and Korchnoy 2006), due to their lack of reflective thinking and conceptual learning skills.

Learning with robots has benefits which are unrelated to students' academic level, as well as benefits which are related to it: collaborative learning in robotic environments can benefit high achieving students by developing their teamwork skills, which are essential for the current workforce (Ananiadou \& Claro, 2009; Korchnoy \& Verner, 2010; National Research Council, 2012; Verner \& Hershko, 2003), and for lower achieving students, the hands-on interdisciplinary activities with robots provide an effective way to learn STEM concepts and acquire technical skills (Cuperman \& Verner, 2013; Spolaôr \& Benitti, 2017).

\section{Implications and recommendations}

Our findings show that the study of student engagement should involve learning processes in different educational tracks, and involve groups of students with different achievement levels, as each group may exhibit distinct patterns of engagement. Another implication of our findings is that monitoring students' engagement is of particular importance for experiential learning in robotic environments, as it allows the teacher to gain a fuller understanding of the students, as individuals and as a group.

This study can serve as a basis for further investigations into student engagement in robotics, and in particular for exploring students of various achievement levels. Teasing out differences in prior knowledge and in learning skills would make for an important contribution to the understanding of how engagement structures vary between students with different academic achievement levels. Future research could also build on the present study and explore student groups in other educational frameworks and contexts, such as 
middle-school or informal education. Observing and analysing the change in individual students' engagement structures over time, as Verner and Revzin (2017), would be another potentially fruitful avenue of research.

The authors can make four recommendations for robotics teachers interested in improving their students' learning engagement:

- Identify each student's internal motivations and use this understanding to facilitate students' autonomy;

- Monitor students' classroom engagement: observe whether or not a student is paying attention, putting forth effort, enjoying class, exploring problems and solutions, and contributing constructively to classroom discussions;

- Employ different strategies for introducing students to robotic technologies and concepts, thereby creating different entry points for engaging students with diverse interests and learning styles; and

- For a given instructional scenario, ascertain the STEM knowledge and skills required for experiential learning with robots, and determine whether students have these knowledge and skills before deciding which instructional approach to apply.

\section{Contribution}

Whereas in most studies on student engagement, observations are conducted over a few months or less, this study involved an entire year of observations. This kind of systematic, long-term observation provides a more reliable portrayal of learning engagement, producing findings and conclusions which add to the theory of engagement structures. Another distinction of this study lies in being one of the first studies on high school robotics student engagement. The study contributes to understanding of student engagement in learning robotics for two different categories of high school students: low achieving students majoring in technology education, and high achieving students who study computer science, a natural science subject, and mechatronics.

The findings and conclusions of this study, and in particular the novel engagement structures and the distinctions that were identified between student achievement groups, can provide educators with a better understanding of their students' needs and behaviours. This study can help teachers identify learning opportunities and more precisely tailor teaching robotics to their students. Additionally, the concept of engagement structures, along with those identified and explained herein, can be included in teacher education and in professional development programs.

\section{Conclusion}

With learning increasingly taking place in technology-rich environments, and being conducted remotely and online, the investigation of student engagement is becoming even more important than before. This is highly pertinent for robotics education, where physical hands-on activities with technological systems are the norm. Currently, a quick Google Scholar search for "robotics education" engagement reveals about 35,000 results, compared with, for example, "mathematics education" engagement, with more than $1,300,000$ results. This indicates that there is still a large scope for investigation of student 
engagement in robotics education. We hope that this study will serve as a basis for future studies that will expand upon this topic.

\section{Declarations}

Conflict of interest Not applicable.

Ethical approval In order to carry out the study, the authors applied and obtained permission from the Behavioral Sciences Research Ethics Committee of the University and the Chief scientist of the Israel Ministry of Education.

Consent to participate The goal and method of our study was explained to the participating students in advance. The participants of this study were students from two high schools. They had the right to cease their participation and exit the study with no ramifications or consequences. The participants' identities were kept anonymous for all our publications; all names were changed and there is no information was disclosed that can be used to recognize any specific individual. The researcher made in-class observations with the consent of the schools' teachers and with the permission of the schools' principals.

Consent for publication All the authors of the manuscript agreed with its content, gave explicit consent to submit it, and obtained consent from the responsible authorities at the University where the work has been carried out.

\section{References}

Alimisis, D. (2013). Educational robotics: Open questions and new challenges. Themes in Science and Technology Education, 6(1), 63-71.

Alonso-Nuez, M. J., Gil-Lacruz, A. I., \& Rosell-Martínez, J. (2020). Assessing evaluation: Why student engages or resists to active learning? International Journal of Technology and Design Education, $1-17$.

Ananiadou, K., \& Claro, M. (2009). 21st century skills and competences for new millennium learners in OECD countries.

Anwar, S., Bascou, N. A., Menekse, M., \& Kardgar, A. (2019). A systematic review of studies on educational robotics. Journal of Pre-College Engineering Education Research, 9(2), 2.

Armier, D. D., Jr., Shepherd, C. E., \& Skrabut, S. (2016). Using game elements to increase student engagement in course assignments. College Teaching, 64(2), 64-72.

Barak, M. (2010). Motivating self-regulated learning in technology education. International Journal of Technology and Design Education, 20(4), 381-401.

Benitti, F. B. V. (2012). Exploring the educational potential of robotics in schools: A systematic review. Computers \& Education, 58(3), 978-988.

Blumenfeld, P. C., Soloway, E., Marx, R. W., Krajcik, J. S., Guzdial, M., \& Palincsar, A. (1991). Motivating project-based learning: Sustaining the doing, supporting the learning. Educational Psychologist, $26(3-4), 369-398$.

Braun, V., \& Clarke, V. (2006). Using thematic analysis in psychology. Qualitative Research in Psychology, $3(2), 77-101$.

Brown, L., Kerwin, R., \& Howard, A. M. (2013). Applying behavioral strategies for student engagement using a robotic educational agent. In 2013 IEEE international conference on systems, man, and cybernetics (pp. 4360-4365).

Church, W. J., Ford, T., Perova, N., \& Rogers, C. (2010). Physics with robotics-using LEGO MINDSTORMS in high school education. In 2010 AAAI Spring symposium series.

Code, J., Ralph, R., \& Forde, K. (2020). Pandemic designs for the future: Perspectives of technology education teachers during COVID-19. Information and Learning Sciences.

Craft, A. M., \& Capraro, R. M. (2017). Science, technology, engineering, and mathematics project-based learning: Merging rigor and relevance to increase student engagement. Electronic International Journal of Education, Arts, and Science, 3(6), 142-158. 
Creswell, J. W., Hanson, W. E., Clark Plano, V. L., \& Morales, A. (2007). Qualitative research designs: Selection and implementation. The Counseling Psychologist, 35(2), 236-264.

Cross, J. L., Hamner, E., Bartley, C., \& Nourbakhsh, I. (2015). Arts \& Bots: Application and outcomes of a secondary school robotics program. In 2015 IEEE frontiers in education conference (FIE) (pp. 1-9). IEEE.

Cuperman, D., \& Verner, I. M. (2013). Learning through creating robotic models of biological systems. International Journal of Technology and Design Education, 23(4), 849-866.

Dong, A., Jong, M. S. Y., \& King, R. B. (2020). How does prior knowledge influence learning Engagement? The mediating roles of cognitive load and help-seeking. Frontiers in Psychology, 11, 1-10.

Goldin, G. A. (2018). Discrete mathematics and the affective dimension of mathematical learning and engagement. In Teaching and learning discrete mathematics worldwide: Curriculum and research (pp. 53-65). Springer, Cham.

Goldin, G. A., Epstein, Y. M., Schorr, R. Y., \& Warner, L. B. (2011). Beliefs and engagement structures: Behind the affective dimension of mathematical learning. ZDM, 43(4), 547.

Green, J. L., Camilli, G., \& Elmore, P. B. (Eds.). (2012). Handbook of complementary methods in education research. Routledge.

Han, S., \& Bhattacharya, K. (2001). Constructionism. Learning by design, and project-based learning. In M. Orey (Ed.), Emerging perspectives on learning, teaching, and technology. Retrieved June, 15, 2008.

Harel, I. E., \& Papert, S. E. (1991). Constructionism. Ablex Publishing.

Hashimoto, T., Kobayashi, H., Polishuk, A., \& Verner, I. (2013). Elementary science lesson delivered by robot. In 2013 8th ACM/IEEE international conference on human-robot interaction (HRI) (pp. 133134). IEEE.

Hatch, J. A. (2002). Doing qualitative research in education settings. Suny Press. Jensen, E. (2013). How poverty affects classroom engagement. Educational Leadership, 70(8), 24-30.

Jensen, E. (2013). How poverty affects classroom engagement. Educational Leadership, 70(8), 24-30.

Jones, B. F., Rasmussen, C. M., \& Moffitt, M. C. (1997). Real-life problem solving: A collaborative approach to interdisciplinary learning. American Psychological Association.

Kaburlasos, V. G., \& Vrochidou, E. (2019). Social robots for pedagogical rehabilitation: Trends and novel modeling principles. In Cyber-physical systems for social applications (pp. 1-21). IGI global.

Kalina, C., \& Powell, K. C. (2009). Cognitive and social constructivism: Developing tools for an effective classroom. Education, 130(2), 241-250.

Kelly, S., \& Price, H. (2009). Vocational education: A clean slate for disengaged students? Social Science Research, 38(4), 810-825.

Khalil, D., Lake, E., \& Johnson, A. (2019). Teachers' classroom engagement structures: A comparative study of a novice US and an experienced UK mathematics teacher. In Affect and mathematics education (pp. 255-282). Springer, Cham.

Korchnoy, E., \& Verner, I. M. (2010). Characteristics of learning computer-controlled mechanisms by teachers and students in a common laboratory environment. International Journal of Technology and Design Education, 20(2), 217-237.

Lee, E., \& Hannafin, M. J. (2016). A design framework for enhancing engagement in student-centered learning: Own it, learn it, and share it. Educational Technology Research and Development, 64(4), $707-734$.

Lee, J. S. (2014). The relationship between student engagement and academic performance: Is it a myth or reality? The Journal of Educational Research, 107(3), 177-185.

Lei, H., Cui, Y., \& Zhou, W. (2018). Relationships between student engagement and academic achievement: A meta-analysis. Social Behavior and Personality: An International Journal, 46(3), 517-528.

Liu, C. C., \& Chen, I. (2010). Evolution of constructivism. Contemporary Issues in Education Research, 3(4), 63-66.

Małgorzata, K., Tanja, B., \& Simon, F. (2018). OECD reviews of vocational education and training apprenticeship and vocational education and training in Israel. OECD Publishing.

National Research Council. (2012). Education for life and work: Developing transferable knowledge and skills in the 21st century. National Academies Press.

Newmann, F. M. (1992). Student engagement and achievement in American secondary schools. Teachers College Press, 1234 Amsterdam Avenue, New York, NY 10027 (paperback: ISBN-0-8077-3182-X, \$17.95; hardcover: ISBN-0-8077-3183-8, \$38).

Papert, S. (1980). Mindstonns (p. 607). Basic Rooks.

Perez, H., \& Verner, I. (2019). Engagement in learning through design and experimentation with robots. In International conference on interactive collaborative learning (pp. 297-305). Springer, Cham. 
Piñeiro, I., Estévez, I., Freire, C., de Caso, A., Souto, A., \& González-Sanmamed, M. (2019). The role of prior achievement as an antecedent to student homework engagement. Frontiers in Psychology, $10(140), 1-8$.

Reeve, J. (2012). A self-determination theory perspective on student engagement. In Handbook of research on student engagement (pp. 149-172). Springer, Boston, MA.

Reimers, F. M., \& Schleicher, A. (2020). A framework to guide an education response to the COVID-19 Pandemic of 2020. OECD. Retrieved April, 14, 2020.

Reynolds, R., \& Caperton, I. H. (2011). Contrasts in student engagement, meaning-making, dislikes, and challenges in a discovery-based program of game design learning. Educational Technology Research and Development, 59(2), 267-289.

Rihtaršič, D., Avsec, S., \& Kocijancic, S. (2016). Experiential learning of electronics subject matter in middle school robotics courses. International Journal of Technology and Design Education, 26(2), 205-224.

Rusk, N., Resnick, M., Berg, R., \& Pezalla-Granlund, M. (2008). New pathways into robotics: Strategies for broadening participation. Journal of Science Education and Technology, 17(1), 59-69.

Schreiber, L. M., \& Valle, B. E. (2013). Social constructivist teaching strategies in the small group classroom. Small Group Research, 44(4), 395-411.

Scruggs, B. (2009). Constructivist practices to increase student engagement in the orchestra classroom. Music Educators Journal, 95(4), 53-59.

Spolaôr, N., \& Benitti, F. B. V. (2017). Robotics applications grounded in learning theories on tertiary education: A systematic review. Computers \& Education, 112, 97-107.

Trowler, V. (2010). Student engagement literature review. The Higher Education Academy, 11(1), 1-15.

Verner, I. (2013). Characteristics of student engagement in robotics. In FIRA RoboWorld congress (pp. 181194). Springer, Berlin, Heidelberg.

Verner, I., \& Korchnoy, E. (2006). Experiential learning through designing robots and motion behaviors: A tiered approach. International Journal of Engineering Education, 22(4), 758-765.

Verner, I. M., \& Hershko, E. (2003). School graduation project in robot design: A case study of team learning experiences and outcomes. 14, 2 (spring 2003).

Verner, I., Massarwe, K., \& Bshouty, D. (2013). Constructs of engagement emerging in an ethnomathematically-based teacher education course. The Journal of Mathematical Behavior, 32(3), 494-507.

Verner, I. M., \& Revzin, L. B. (2017). Robotics in school chemistry laboratories. In Robotics in education (pp. 127-136). Springer, Cham.

Wu, H. K., \& Huang, Y. L. (2007). Ninth-grade student engagement in teacher-centered and student-centered technology-enhanced learning environments. Science Education, 91(5), 727-749.

You, Z. J., Shen, C. Y., Chang, C. W., Liu, B. J., \& Chen, G. D. (2006). A robot as a teaching assistant in an English class. In Sixth IEEE international conference on advanced learning technologies (ICALT'06) (pp. 87-91).

Publisher's Note Springer Nature remains neutral with regard to jurisdictional claims in published maps and institutional affiliations. 